\title{
ANALISIS KEBUTUHAN PENGEMBANGAN BAHAN AJAR MATA KULIAH BUDAYA LOKAL DI IAIN PALANGKA RAYA
}

\author{
Analysis of Needs Development Material learning Program local cultural \\ in State Islamic Institute of Palangka Raya
}

Jasiah

Program Studi Pendidikan Guru

Madrasah Ibtidayah

FTIK IAIN Palangkaraya

*email:

jasiah@iain-palangkaraya.ac.id

\section{Kata Kunci:}

Analisis

Bahan Ajar

Budaya Lokal

Keywords:

Analysis

Teaching Materials

Local Culture

Accepted

September 2019

Published

December 2019

\begin{abstract}
Abstrak
Bahan ajar pada proses pembelajaran memegang peranan yang sangat penting. Jika dosen dapat memanfaatkan bahan ajar secara baik, maka dosen dapat berbagi peran dengan bahan ajar. Selain itu dosen yang menggunakan bahan ajar yang tepat dapat menghemat waktu dalam mengajar dan dapat mengubah peran dosen dari seorang pengajar menjadi fasilitator, serta dapat meningkatkan proses pembelajaran menjadi lebih efektif dan interaktif. Bagi mahasiswa, bahan ajar dapat membantu menjadi pembelajar yang mandiri dan dapat digunakan untuk mengukur kompetensi yang telah dimiliki oleh mahasiswa. Mata kuliah budaya lokal merupakan mata kuliah pilihan yang diprogramkan pada semester enam dan tercantum pada kurikulum 2017 program studi pendidkan guru madrasah ibtiayah. Bahan ajar yang selama ini digunakan dalam kegiatan pembelajaran merupakan bahan ajar sederhana yang dibuat oleh dosen dengan mengggunakan referensi dari internet dan buku yang sangat minim. Tujuan penelitian ini adalah untuk mengetahui kebutuhan mahasiswa terhadap bahan ajar mata kuliah budaya lokal. Subjek penelitian adalah mahasiswa Angkatan 2017, berjumlah 25 orang Data dikumpulkan dengan menggunakan lembar observasi kegiatan perkuliahan dan angket terbuka untuk mahasiswa. Hasil observasi menunjukkan bahwa kendala yang dihadapi pada pembelajaran mata kuliah budaya lokal adalah belum ada bahan ajar yang bisa dijadikan sebagai pegangan dalam proses pembelajaran. Hasil analisis angket kebutuhan mahasiswa terhadap bahan ajar menunjukkan bahwa bahan ajar diperlukan oleh mahasiswa adalah berupa modul dan buku ajar.
\end{abstract}

\section{Abstract}

Teaching materials in the learning process plays a very important. If the teacher can utilize the teaching materials as well, then the faculty can share the role with teaching materials. Besides lecturers using appropriate teaching materials can save time in teaching and lecturers can change the role of a teacher becomes a facilitator, and to improve the learning process becomes more effective and interactive. For students, teaching materials can help learners become independent and can be used to measure the competence that has been owned by students. The local culture course is programmed elective courses in the sixth semester of 2017 and listed on the curriculum of Study Program of Madrasah Ibtidaiyah teacher education courses. Teaching materials that have been used in the learning activities is a simple teaching material prepared by the lecturer by using a reference from the internet and books are minimal. The purpose of this study was to determine the needs of students to instructional materials subject to local culture. The research subject was a student from 2017, amounting to 25 data was collected using observation sheets and questionnaires lectures open to students. Observations show that the obstacles encountered in the course of learning the local culture is not teaching materials that can be used as a handle in the learning process. The results of the questionnaire analysis needs of students to instructional materials show that the teaching materials needed by the students is in the form of modules and textbooks. 


\section{PENDAHULUAN}

Pembelajaran adalah proses interaksi peserta didik dengan guru dan sumber belajar pada suatu lingkungan belajar. Proses pembelajaran tersebut perlu direncanakan, dilaksanakan, dinilai, dan diawasi agar terlaksana secara efektif dan efesien.

Proses pembelajaran pada setiap satuan pendidikan harus interaktif, inspiratif, menyenangkan, menantang, dan memotivasi peserta didik untuk berpartisipasi secara aktif, serta memberikan ruang yang cukup bagi prakarya, dan perkembangan fisik serta psikologis peserta didik

Upaya pemerintah Indonesia dalam mencerdaskan bangsa salah satunya pendidikan. Pendidikan di lakukan untuk mewujudkan masyarakat yang sejahtera, baik dari segi kualitas maupun kuantitas pengetahuan yang di milikinya. Keberhasilan pendidikan bermutu sesuai harapan pemerintah di tentukan oleh proses pendidikan yang di alami oleh peserta didik, begitu juga dengan kompetensi pengajar yang tepat. Adanya dukungan sistem sarana dan prasarana serta media pembelajaran yang menopang proses belajar mengajar sangat penting untuk di berikan kepada peserta didik, karena hal ini menyangkut aspek perkembangan kognitif peserta didik sebagai objek utama dalam kegiatan belajar mengajar setiap hari. Ada beberapa hal yang perlu di perhatikan dalam pembelajaran: (I) Apa yang diajarkan; berkaitan dengan tujuan dan materi yang diajarkan, (2) Bagaimana cara mengajarnya; menyangkut metode mengajar dan alat peraga apa yang akan di gunakan dalam pembelajaran, (3) Bagaimana cara mengetahui bahwa yang di ajarkan dapat dipahami siswa; berkaitan dengan cara mengevaluasi terhadap materi yang telah di ajarkan.

Semakin berkembangnya ilmu pengetahuan dan teknologi dalam dunia pendidikan maka tuntutan kemajuan sumber daya manusia sangat di perlukan, serta peningkatan kualitas pendidikan juga sangat di perlukan, bukanlah suatu pekerjaan yang mudah, tetapi tidak sulit untuk di usahakan jika ada keinginan yang kuat untuk meningkatkan efektifitas dan efesiensi dari berbagai aspek pendidikan.

Selanjutnya, dalam konteks proses belajar mengajar di Indonesia, Syamsuddin menambahkan satu peran lagi yaitu sebagai pembimbing (teacher counsul), di mana guru dituntut untuk mampu mengidentifikasi peserta didik yang diduga mengalami kesulitan dalam belajar, melakukan diagnosa, prognosa, dan kalau masih dalam batas kewenangannya, harus membantu pemecahannya (remedial teaching). Peran guru di sini sangat penting dalm meningkatkan kualitas pembelajaran. Seperti yang telah di kemukankan Degeng (200I), upaya untuk meningkatkan kualitas pembelajaran dilakukan oleh perancang pembelajaran dengan pijakan asumsiasumsi tertentu tentang desain pembelajaran, antara lain: (I) Perbaikan kualitas pembelajaran di awali dari desain pembelajaran, (2) Desain pembelajaran di dasarkan pada pengetahuan tentang bagaimana seseorang belajar, (3) Desain pembelajaran diacukan pada si pebelajar, (4) Hasil pembelajaran mencakup hasil langsung dan hasil pengiring, (5) Sasaran akhir desain adalah memudahkan belajar, (6) desain pembelajaran mencakup semua variabel yang mempengaruhi belajar, dan (7) Inti desain adalah menetapkan metode pembelajaran yang optimal untuk mencapai tujuan yang di tetapkan. Menurut Hamdani (201I: 120) menyebutkan "bahan ajar adalah segala bentuk bahan atau materi yang disusun secara sistematis yang digunakan untuk membantu guru atau instrukstur dalam melaksanakan kegiatan belajar mengajar sehingga tercipta lingkungan atau suasana yang memungkinkan siswa untuk belajar." Yang dimaksud bahan ajar adalah segala bentuk bahan yang disusun secara sistematis untuk digunakan dosen atau mahasiswa dalam membantu pelaksanaan kegiatan belajar mengajar baik di kelas maupun di luar kelas.

Bahan ajar merupakan salah satu komponen yang memegang peranan penting dalam proses pembelajaran. Menurut Reza dkk (2016) bahan ajar merupakan salah satu komponen yang dapat membantu kelancaran belajar siswa maupun mahasiswa. Bahan ajar adalah segala bentuk bahan yang digunakan untuk membantu guru/instruktor dalam melaksanakan kegiatan belajar mengajar di kelas (Prastowo, 2012). Bahan yang dimaksud bisa berupa bahan tertulis maupun bahan tidak tertulis. Secara garis besar bahan ajar terdiri atas dua jenis, yaitu bahan ajar cetak dan bahan ajar non cetak. Contoh bahan ajar cetak adalah buku teks, buku ajar, handout, modul, poster, dan leaflet, sedangkan bahan ajar non cetak dapat berupa bahan ajar audio seperti kaset, radio, bahan ajar visual seperti gambar, foto, maupun bahan ajar audiovisual seperti video/film.

Hamdani (201 I:I22) menyebutkan bahwa bahan ajar disusun dengan tujuan yaitu : membantu pembelajar dalam membuka wacana dan wahana baru, menyediakan bahan ajar yang beragam, memudahkan proses pembelajaran dan menarik. Agar bahan ajar menjadi bermakna, maka seorang pendidik dituntut untuk dapat secara kreatif mendesain suatu bahan ajar yang memungkinkan peserta didik dapat secara mudah memahami materi dan secara langsung dapat memanfaatkan sumber belajar yang tersedia, misalkan dengan cara desain bahan ajar, agar guru dapat terdahulu mengetahui masalah-masalah yang dialami 
siswa dan menyesuaikan dengan bahan ajar yang akan dibuat.

Prastowo (20I5: 24-26) mengklasifikasi fungsi bahan ajar dari aspek piihak yang memanfaatkan yaitu pendidik dan peserta didik sedangkan dari aspek strategi pembelajaran yang digunakan yaitu pembelajaran klasikal, individual dan pembelajaran kelompok. Sedangkan kegunaan bahan ajar untuk pendiidik yaitu memudahkan proses pembelajaran, sebuah karya yang diinilai dan menambah penghasilan jika bhan ajar diterbitkan. Adapun kegunaan untuk peserta didk yaitu proses pembelajaran lebih menarik, dapat belajar mandiri serta memudahkan untuk menguasai kompetensi yang diharapkan.

Bahan ajar pada proses pembelajaran memegang peranan yang sangat penting. Jika dosen dapat memanfaatkan bahan ajar secara baik, maka dosen dapat berbagi peran dengan bahan ajar. Selain itu dosen yang menggunakan bahan ajar yang tepat dapat menghemat waktu dalam mengajar dan dapat mengubah peran dosen dari seorang pengajar menjadi fasilitator, serta dapat meningkatkan proses pembelajaran menjadi lebih efektif dan interaktif. Bagi mahasiswa, bahan ajar dapat membantu menjadi pembelajar yang mandiri dan dapat digunakan untuk mengukur kompetensi yang telah dimiliki oleh mahasiswa.

Proses pembelajaran yang berlangsung selama ini mahasiswa belum memiliki bahan ajar yang sama yang digunakan sebagai pegangan dalam proses pembelajaran yang dapat mempermudah proses pembelajaran. Mahasiswa memperoleh materi pembelajaran selain dari internet dan dari buku teks. Mahasiswa sangat tergantung kepada dosen, terutama kaitannya dengan materi pembelajaran. Dosen menjadi sumber belajar yang utama dalam proses pembelajaran sehingga perlu adanya bahan ajar yang dirancang dan dikembangkan oleh dosen untuk mempermudah mahasiswa dalam memahami materi perkuliahan, kesamaan materi yang dipelajari oleh mahasiswa serta bahan ajar dapat menjadi pegangan baik bagi dosen maupun bagi mahasiswa dalam proses pembelajaran.

Tujuan penelitian ini adalah untuk mengetahui kebutuhan bahan ajar yang sesuai dengan kebutuhan mahasiswa di program studi Guru Madrasah Ibtidayah IAIN Palangka Raya. Hasil dari penelitian ini diharapkan dapat memberikan informasi awal mengenai bahan ajar yang perlu dikembangkan dan materi pembelajaran apa saja yang harus ada di dalam bahan ajar tersebut. Selanjutnya hasil dari penelitian ini digunakan untuk mengembangkan bahan ajar pada penelitian selanjutnya

\section{METODE PENELITIAN}

Penelitian dilaksanakan dari bulan Agustus oktober 2019 di Jurusan Tarbiyah FTIK IAIN Palangka Raya Subyek penelitian adalah seluruh mahasiswa semester genap program studi PGMI yang mengambil mata kuliah budaya lokal berjumlah 25 mahasiswa. Jenis penelitian ini menggunakan analisis deskriptif kualitatif dengan metode survey. Teknik pengumpulan data dengan wawancara, observasi dan angket. Instrumen pengumpulan data dengan menggunakan lembar observasi dan angket. Lembar observasi digunakan untuk memperoleh data tentang proses pembelajaran mata kuliah budaya lokal. Angket terbuka digunakan untuk memperoleh data tentang sumber belajar yang selama ini digunakan oleh mahasiswa dan kebutuhan bahan ajar yang diinginkan oleh mahasiwa.

\section{HASIL DAN PEMBAHASAN}

Berdasarkan hasil observasi selama perkuliahan mata kuliah budaya lokal diperoleh data sebagaimana tertuang pada tabel I. Data hasil angket yang disebarkan pada mahasiswa tentang sumber belajar yang diigunakan mahasiswa sebagaimana tertuang pada tabel 2. Sedangkan data hasil angket yang disebarkan kepada mahasiswa terkait bahan ajar yang dibutuhkan mahasiswa tertuang pada tabel 3.

Tabel I. Hasil observasi pembelajaran mata kuliah budaya lokal

No Hasil Observasi

I. Mahasiswa belum fokus dalam proses pembelajaran karena belum memiliki buku acuan yang digunakan dalam proses pembelajaran

2. Sumber belajar yang digunakan oleh mahasiswa berasal dari internet

3. Beberapa mahasiswa belum terlalu aktif dalam proses pembelajaran, masih cenderung pasif

4. Ada mahasiswa yang berbicara sendiri dengan temannya pada saat proses pembelajaran

5. Dosen belum memilki buku pegangan yang dapat dijadikan sebagai bahan ajar dalam proses pembelajaran

6. Dosen masih menjadi sumber belajar utama 
Tabel 2. Sumber belajar mahasiwa

\begin{tabular}{clc}
\hline No & Jenis Sumber Belajar & Jumlah (\%) \\
\hline 1 & Internet & 43,36 \\
2 & Dosen & 33,28 \\
3 & Buku teks & 15,76 \\
\hline
\end{tabular}

\begin{tabular}{ll}
\hline & \\
\hline No & Jenis Bahan Ajar \\
\hline 1 & Buku Ajar \\
2 & Modul \\
3 & Power \\
& 10,38
\end{tabular}

Berdasarkan hasil observasi yang dilakukan selama proses perkuliahan pada mata kuliah budaya lokal diperoleh data bahwa sebagian besar dari mahasiswa belum fokus dalam proses pembelajaran hal ini dikarenakan belum adanya bahan ajar yang dapat digunakan sebagai pegangan oleh mahasiswa. Belum adanya bahan ajar yang dimiliki oleh mahasiswa menjadikan mahasiswa belum mempersiapkan materi yang akan dipelajari. Karena mahasiswa belum memilki kesiapan sehingga pembelajaran cenderung berjalan satu arah, pada saat diskusi maupun tanya jawab belum seluruh mahasiswa mampu berpartisipasi. Dan lebih dari $30 \%$ hasil angket dari mahasiwa bahwa sumber belajar adalah dosen.

Sumber belajar yang digunakan oleh mahasiswa dalam perkuliahan berupa artikel-artikel maupun tulisan-tulisan tentang budaya lokal didownload dari internet.Sementara artikel- artikel yang diambil mahasiswa dari internet keakuratan data dan sumber referensinya belum diketahui kebenarannya. Selain itu, materi yang diperoleh dari buku teks sebagian besar hanya mengupas tentang budaya lokal secara secara umum dan kalaupun ada masih sangat terbatas untuk pembahasan yang mendalam mengenai budaya lokal Kalimantan Tengah.

Berdasarkan angket yang dibagikan kepada mahasiswa diperoleh data bahwa mahasiswa menginginkan adanya bahan ajar yang dikembangkan sendiri oleh dosen mata kuliah dengan menggunakan bahasa yang mudah dipahami oleh mahasiswa, ringkas, dan terdapat soal latihan. Sedangkan jenis bahan ajar yang diinginkan oleh mahasiswa $42.56 \%$ mahasiswa menginginkan adanya modul.

Modul merupakan salah satu jenis bahan ajar yang dapat dijadikan sebagai pegangan bagi mahasiswa dan dosen dalam melaksanakan kegiatan perkuliahan. Modul memiliki karakter yang berbeda

\begin{tabular}{r} 
Jumlah (\%) \\
\hline 24,97 \\
42,56
\end{tabular}

denan buku-buku referensi point/tayangan Penyusunan modul disesuaikan dengan kurikulum, ditulis dan dirancang berdasarkan kebutuhan pembelajar, menggunakan bahasa yang komunikatif, merujuk kepada kompetensi yang harus dicapai, disusun untuk proses instruksional, seluruh materi yang dibutuhkan tercantum dan memiliki mekanisme umpan balik dari peserta didik. Secara umum dapat dikatakan bahwa modul dapat mengembangkan potensi peserta didik menjadi pembelajar mandiri.

Senada dengan keinginan mahasiswa dibutuhkannya bahan ajar untuk mata kuliah budaya lokal berdasarkan hasil wawancara dengan dosen pengampu bahwa sumber belajar berupa buku sangat sediikit sebagai refrensi untuk mata kuliah budaya lokal Kalimantan Tengah bahkan bahan ajar untuk mata kuliah budaya lokal di IAIN Palangka Raya tidak ada.

Pengembangan bahan ajar yang akan dilaksanakan merujuk pada prosedur pengembangan model ADDIE yang dikembangkan oleh Dickk and Carry (1996) yang terdiri atas Analysis Design, Development, Implementatiiion, Evaluaton,. Alasan pemilihan model ADDIE didasarkan pada tiap tahapan saling berkaitan dan terstruktur secara sistematis. Prosedur yang digunakan dalam model ini lebih rasional, mudah dipahami dan dipraktikan, sehingga model ini sesuai digunakan untuk pengembangan bahan ajar.

\section{SIIMPULAN}

Berdasarkan data hasl penelitian dan pembahasan yang telah didesripsikan maka dapat disimpulkan bahwa kendala yang dihadapi pada proses pembelajaran mata kuliah budaya lokal adalah belum adanya bahan ajar yang perlu dikembangkan pada mata kuliah budaya lokal untuk mahasiswa program studi Pendidikan Guru Madrasah Ibtidayah FTIK IAIN Palangka Raya dapat berupa modul dan buku ajar. 


\section{DAFTAR PUSTAKA}

Abin Syamsuddin Makmun, (2003), Psikologi Pendidikan, Bandung, Rosda Karya

Anderson, Ronald H., (1987) Pemilihan dan Pengembangan Media untuk Pembelajaran, Jakarta : Rajawali

Arsyad, Azhar, (2000) Media Pengajaran, Jakarta : PT. Raja Grafindo Persada,

Degeng, (200I), Teori Belajar dan Strategi Pembelajaran, Surabaya, Citra Raya

Irawati Hani, Syaifiddin Much Fuad. 2018. Analisis Kebutuhan Pengembangan bahan Ajar Mata Kuliah Pengantar Profesi Guru Biologi di Pendidikan Biologi Universitas Ahmad Dahlan Yogyakarta. Bio Pedagogik: Jurnal Pembelajaran Biologi, Volume 7, Nomor 2 hal 96-99

Hamdani, (20II), Strategi Belajar Mengajar, Bandung, Pustaka Setia

Mustaji. (2009). Teori dan model pembelajaran. Surabaya: Unesa University Press.
Prastowo, Andi. 201I. Panduan Kreatif Membuat Bahan Ajar Inovatif (Menciptakan Metode Pembelajaran yang Menarik dan Menyenangkan). Jogjakarta: Diva Press.

Seels, B. B. dan Carey. R (1994). Teknologi Pembelajaran: Definisi dan Kawasannya. Diterjemahkan oleh Dra. Dewi S. Prawiradilaga, M.Sc. dkk. Dari buku aslinya Instructional Technology: The Definition and domain of the field. Jakarta: Unit Percetakan Universitas Negeri Jakarta.

Rusijono dan Mustaji. (2008). Penelitian teknologi pembelajaran. Surabaya: Unesa University Press

Suparman, Atwi. (200I). Desain Interuksional. Jakarta: Rineka Cipta

Zanuszewski (2008). Educational technology : A definition with commentary. The state university of NewYork as postda 